\title{
Lighting intensity in university libraries of Rafsanjan, Iran, in 2014
}

\author{
Esmaeili A, $\mathrm{PhD}^{1}$, Rezaeian $\mathrm{M}, \mathrm{PhD}^{2}$, Naghizadeh HR, BSc${ }^{3}$, Khajehosseini Sh, $\mathrm{BSc}^{4}$, \\ Mobini M, MSc ${ }^{5 *}$
}

1- Associated Prof., Dept. of Environmental Health Engineering, School of Health, Occupational Environment Research Center, Rafsanjan University of Medical Sciences, Rafsanjan, Iran. 2- Professor, Dept. of Epidemiology and Biostatistics, Occupational Environmental Research Center, Medical School, Rafsanjan University of Medical Sciences, Rafsanjan, Iran. 3- BSc in Occupational Health, Deputy of Health, Rafsanjan University of Medical Sciences, Rafsanjan, Iran. 4- MSc Student in Critical Nursing, School of Nursing and Midwifery, Rafsanjan University of Medical Sciences, Rafsanjan, Iran. 5- MSc in Environmental Health Engineering, Dept. of Environmental Health Engineering, School of Health, Rafsanjan University of Medical Sciences, Rafsanjan, Iran.

Background: Lighting is a basic need for human beings and affects their physical, physiological, and psychological behavior. The required level of lighting for visual performance must be provided in order to ensure health and wellbeing. Students spend much of their time studying in libraries, and thus, sufficient lighting is necessary in libraries. Therefore, the aim of the present study was to determine lighting intensity in university libraries in Rafsanjan, Iran.

Materials and Methods: The present cross-sectional study was conducted on 13 university libraries of Rafsanjan in April 2014. To assess natural and total lighting intensity, the network method was used. Lighting intensity was measured in a total of 314 stations in the university libraries of Rafsanjan. The collected data were analyzed using descriptive statistics.

Results: The men's section of the library of Vali-E-Asr University of Rafsanjan had the highest total lighting intensity (1265.40 $\pm 530.95 \mathrm{~lx})$ and the men's section of the library of the School of Medicine, Rafsanjan University of Medical Sciences, had the lowest total lighting intensity (91.06 \pm 29.40 lx). Among the 13 study halls of the studied libraries, 4 (30.7\%) halls had no windows. The lack of windows has an undesirable effect on the intensity of natural lighting.

Conclusions: Based on the results of this study, the average lighting intensity in $50 \%$ of the studied libraries was less than the Iranian standard. Therefore, the redesigning and modification of the lighting systems of these libraries are necessary.

Keywords: Lighting, Libraries, Universities, Iran.

\section{Introduction}

Lighting is a basic need for human beings and affects their physical, physiological, and psychological behavior. The required level of lighting for visual performance must be provided in order to ensure health and wellbeing (1). Environmental lighting impacts the speed and quality of work, sleep, absenteeism, and incidents in the workplace. Lighting does not only affect visual perception, but also nonvisual responses such as mental and physiological responses $(2,3)$.
Some important processes related to controlling the biological clock and hormone regulation are associated with the regulation of the light-dark cycle $(4,5)$. Cortisol (stress hormone) and melatonin (sleep hormone) have an important role in sleep and consciousness. Cortisol increases the blood sugar and provides the body with energy, and

\footnotetext{
* Corresponding author: Mohammad Mobini, Dept. of Environmental Health Engineering, School of Health, Rafsanjan University of Medical Sciences, Rafsanjan, Iran. E-mail: mobinilk@gmail.com
} 
strengthens the immune system. Melatonin increases at night and in darkness and results in healthy sleep (6). Some of the advantages of appropriate lighting ensure the health and wellbeing of workers and result in their better work performance, fewer errors, higher safety, and most importantly, increased productivity (7).

De Kort et al. and Scheer et al. found that the amount of light impacts psychologicalbiological processes and individuals exposed to higher amount of light were more conscious, less fatigued, and more energetic compared to individuals exposed to lower amounts of light $(7,8)$.

Contrary to offices, in which employees' position in respect to their desk is static, the library environment consists of areas with different characteristics, such as group desks, comfortable chairs, and areas for individuals study. This approach accommodates the needs of a wide range of consumers in respect to various lighting. Therefore, high quality lighting with sufficient glare must be provided in all areas of the library (9).

Students spend a relatively large part of their time studying in libraries and lighting of less than $30 \mathrm{~lx}$ causes eye fatigue (10). Therefore, appropriate lighting and its optimal distribution is of great importance in libraries for the prevention of eye fatigue and reduced accuracy (11). The standard lighting on the study desk in Iran is a minimum of $300 \mathrm{~lx}$ and the recommended amount is $500 \mathrm{~lx}$ (12).

The result of studies on the intensity of lighting in libraries in different areas of Iran have shown that lighting intensity in libraries was lower than the standard amount due to reasons such as unsuitable design, unsuitable lighting sources, old buildings used as libraries, unsuitable lamp arrangement, positioning of lamps at unsuitable heights, lack of windows, and lack of suitable use of artificial lighting (11, 13-15). These shortcomings must be addressed using engineering processes.

Considering the importance of suitable lighting in libraries (9), the present study was conducted to determine the intensity of lighting in libraries of universities in Rafsanjan, Iran, so that appropriate solutions could be provided for library lighting.

\section{Material and Methods}

Rafsanjan is located at the latitude of 30 degrees north and longitude of 56 degrees east. Rafsanjan has a warm and dry climate and its mean annual sunshine duration is 3362.65 hours (16). Rafsanjan has 6 universities; Rafsanjan University of Medical Sciences (2000 students), Vali-E-Asr University of Rafsanjan (10000 students), Islamic Azad University (3000 students), Payame Noor University (1600 students), Allameh Jafari University (1000 students), and Islamic Kar University (300 students).

This cross-sectional study was conducted in all libraries of universities in Rafsanjan in April 2014. The libraries studied consisted of the libraries of the School of Medicine, School of Nursing and Midwifery, and the School of Dentistry of Rafsanjan University of Medical Sciences and the libraries of Vali-E-Asr University of Rafsanjan, Islamic Azad University, Payame Noor University, Allameh Jafari University, and Islamic Kar University.

To assess natural and total lighting intensity, the network method was used. In this method, each library was divided into $2 \times 2 \mathrm{~cm}$ stations using a tape measure, and lighting intensity was measured at the center of each station (10).

Lighting intensity was measured in a total of 314 stations in the university libraries of Rafsanjan using the Hagner Digital Luxmeter (model EC1, Hagner®, Solna, Sweden).

To measure the intensity of lighting, the luxmeter was placed at a height of $60 \mathrm{~cm}$ above the ground and the center of the station based on similar studies (11, 13-15). All lamps were switched off during measurement of natural lighting and all lamps were switched on during measurement of total lighting. Measurements were performed at 9-12 a.m. and were not performed on cloudy days. The 
studied libraries were not open at night; therefore, artificial lighting was not measured in the present study. The intensity of lighting in each station was recorded in lux; illumination by the optical flux of a lumen on a surface of $1 \mathrm{~m}^{2}$ (12). The mean and standard deviation of lighting intensity in each library was determined using Microsoft Office Excel 2007 (Microsoft Redmond campus, Redmond, WA, USA) and was compared to the standards.

\section{Results}

The findings of the present study showed that the men's section of the library of Vali-E-Asr University of Rafsanjan had the highest total lighting intensity $(1265.40 \pm 530.95 \mathrm{~lx})$ and the men's section of the library of the School of Medicine, Rafsanjan University of Medical Sciences, had the lowest total lighting intensity $(91.06 \pm 29.401 \mathrm{~lx})$.

Based on the results presented in table 1, the highest intensity of natural lighting was related to the men's section of the library of Vali-EAsr University of Rafsanjan and the lowest intensity was related to the women's section of the libraries of the School of Medicine, School of Dentistry, and Islamic Azad University. Among the 13 study halls of the studied libraries, $4(30.7 \%)$ halls had no windows. The lack of windows has an undesirable effect on the intensity of natural lighting. Moreover, the mean and standard deviation of the total and natural lighting intensity and the ratio of window area to floor area of the studied university libraries are presented in table 1 .

Table 1: Mean and standard deviation of the total and natural lighting intensity and the ratio of window area to floor area of the university libraries in Rafsanjan in April 2014

\begin{tabular}{|c|c|c|c|}
\hline Library & $\frac{\text { Total lighting (lux) }}{\text { Mean } \pm \text { SD }}$ & $\frac{\text { Natural lighting (lux) }}{\text { Mean } \pm \text { SD }^{*}}$ & $\begin{array}{c}\text { Ratio of window area } \\
\text { to floor area }(\%)\end{array}$ \\
\hline School of Medicine - men's section & $91.06 \pm 29.4$ & $2.77 \pm 1.09$ & No windows \\
\hline $\begin{array}{c}\text { School of Medicine - women's } \\
\text { section }\end{array}$ & $293.54 \pm 98.22$ & $24.54 \pm 17.16$ & No windows \\
\hline School of Nursing and Midwifery & $194.5 \pm 20.18$ & $61.8 \pm 33$ & 7.98 \\
\hline School of Dentistry - men's section & $515.44 \pm 217.76$ & $240.9 \pm 121.04$ & 11.25 \\
\hline $\begin{array}{c}\text { School of Dentistry - women's } \\
\text { section }\end{array}$ & $114 \pm 42.42$ & $8 \pm 3.42$ & No windows \\
\hline $\begin{array}{l}\text { Vali-E-Asr University of } \\
\text { Rafsanjan - men's section }\end{array}$ & $1265.4 \pm 530.95$ & $867.9 \pm 700.48$ & 6.44 \\
\hline $\begin{array}{c}\text { Vali-E-Asr University of } \\
\text { Rafsanjan - women's section }\end{array}$ & $750.5 \pm 243.58$ & $273.3 \pm 177.9$ & 8.2 \\
\hline $\begin{array}{c}\text { Payame Noor University - men's } \\
\text { section }\end{array}$ & $571.87 \pm 581.81$ & $462.5 \pm 409.55$ & 72.67 \\
\hline $\begin{array}{c}\text { Payame Noor University - } \\
\text { women's section }\end{array}$ & $722.69 \pm 588.32$ & $543.15 \pm 546.08$ & 19 \\
\hline $\begin{array}{c}\text { Islamic Azad University - men's } \\
\text { section }\end{array}$ & $212.78 \pm 70.55$ & $15.35 \pm 7.06$ & No windows \\
\hline $\begin{array}{c}\text { Islamic Azad University - women's } \\
\text { section }\end{array}$ & $222.78 \pm 161.73$ & $140 \pm 181.8$ & 13.11 \\
\hline Allameh Jafari University & $543.75 \pm 192.93$ & $174.87 \pm 114.11$ & 17.5 \\
\hline Kar University & $374 \pm 248.67$ & $223.84 \pm 386.08$ & 15.43 \\
\hline
\end{tabular}

*The high standard deviation is due to the high length of some of the halls (a long distance from the windows); the lighting intensity was high near the windows and lower at the other end of the hall.

\section{Discussion}

The intensity of lighting in libraries and study halls differs due to various causes such as geographic location of the region, geographical location of the library, and the number, area, and location of the windows, color of the library, height and type of lamps, and the arrangement of the lighting system 
(13-15). In the present study, total lighting in most libraries of Rafsanjan University of Medical Sciences and Islamic Azad University was at least $300 \mathrm{~lx}$ less than the standard amount in Iran and $500 \mathrm{~lx}$ less than the recommended amount (12). These libraries lacked windows; thus, their natural lighting was extremely low.

Javan et al. conducted a study on the lighting intensity of study halls of the dormitories of Isfahan University of Medical Sciences, Iran (13). The found that from among 24 evaluated study halls, the mean total and natural lighting intensity of 21 and 9 study halls, respectively, was higher than $300 \mathrm{~lx}$ and the ratio of window area to floor area was less than $25 \%$ in the majority of cases (13). This is not in agreement with the results of the present study. The study by Javan et al. was conducted in February; thus, it is indicative of the sufficient amount of windows, more suitable lighting source, and the better design of the library of Isfahan University of Medical Sciences compared to the university libraries of Rafsanjan.

Ghotbi et al. evaluated lighting intensity and ultraviolet radiation in 14 study halls in libraries of Kerman University of Medical Sciences, Iran (11). They found that total and natural lighting intensity were, respectively, lower than the standard amount in $28.5 \%$ and $100 \%$ of study halls (11), which is in agreement with the findings of the present study. Ghotbi et al. recommended the correct arrangement and periodical cleaning of lamps and correct coloring of library buildings in order to increase lighting intensity (11).

Winterbottom et al. assessed flickering and intensity of lighting on the surface of tables and interactive whiteboards in 90 classes in high schools and educational centers of University of Cambridge, UK (17). They found that $80 \%$ of classes had fluorescent lighting of $100 \mathrm{~Hz}$ which can causes headaches and visual impairment (17). Moreover, the mean lighting of $88 \%$ of classes was higher than the recommended lighting design and was excessively high on $84 \%$ of surfaces which reduced visual comfort. They also found that due to the design and infrastructure of classes, lighting could not be controlled sufficiently (17). The findings of this study was in accordance with that of the present study on the libraries of Vali-e-Asr University of Rafsanjan, and Payame Noor University, in which lighting intensity was higher than $500 \mathrm{~lx}$ due to the high number of windows and natural lighting.

The use of natural lighting is of great importance, especially in desert regions that enjoy this divine blessing throughout the year. Due to the easy access and antiseptic properties of natural light, and the low price of public places, especially libraries of scientific centers, these locations must be designed in a way to use the maximum natural light possible (18).

Espinoza et al. assessed the rate of sound and light in the central facilities of the University of Costa Rica, Republic of Costa Rica, and its health outcomes on employees and students (19). They reported that the lighting intensity was not satisfactory and the redesigning of artificial lighting was necessary (19). The findings of this study are in close agreement with the present study.

The results of the study by Zamanian et al. illustrated a significant relationship between lighting intensity and students' posture. When individuals experience an external stress, they change their body posture (status) in order to decrease stress. Due to this change, the body goes from a neutral state to an unsatisfactory state which causes undesirable biomechanical pressure on the musculoskeletal structure, and thus, musculoskeletal disorders (20). Therefore, lighting in the standard range is necessary to increase productivity and reduce health risks.

The results of the studies by MaghsoudiMoghaddam et al. on the lighting intensity of libraries and computer room of the University of Ilam, Iran (15), Nadri et al. on the measurement and designing of general lighting intensity in the dormitories of Qazvin University of Medical Sciences, Qazvin, Iran 
(14), and Majidi et al. on the lighting intensity of libraries with irregular geometric shapes in Zanjan, Iran (21), were in accordance with the results of the present study. The abovementioned researchers have recommended the redesigning of the lighting system of these locations.

The limitations of the present study were the unavailability of a device for the measurement of ultraviolet radiation caused by fluorescent lamps and the inability to measure artificial lighting in the libraries due to their working hours. It is suggested that, in addition to university libraries, the lighting intensity and ultraviolet radiation of libraries and study halls of dormitory, hospitals, educational departments, and if possible public libraries be assessed so that suggestions can be provided for the better use and efficiency of libraries. In addition to lighting, the ambient sound of libraries impacts concentration and higher efficiency in studying; thus, it is suggested that lighting and sound be measured in libraries and dormitories and suitable solutions be provided.

\section{Conclusion}

Based on the results of the present study, the mean lighting intensity in $50 \%$ of the studied libraries was less than the Iranian standard. Hence, considering the physiological effects of light on the body, and thus, its impact on the productivity of individuals, corrective measures such as the redesigning and modification of lighting systems, and if financially possible the building of libraries with suitable designs based on standards are necessary.

\section{Acknowledgements}

The present study was performed in the Occupational Environment Research Center of Rafsanjan University of Medical Sciences and received funding from the Deputy for Education and Research of this university. The authors wish to thank the authorities of the studied libraries for their cooperation in turning off artificial lighting and providing information on the libraries' structures.

Conflict of interests: None declared.

\section{References}

1. Bellia L, Bisegna F, Spad G. Lighting in indoor environments: visual and non-visual effects of light sources with different spectral power distributions. Build Environ 2011; 46(10):1984-92.

2. Hoffmann G, Gufler V, Griesmacher A, Bartenbach C, Canazeic M, Staggl S, et al. Effects of variable lighting intensities and colour temperatures on sulphatoxymelatonin and subjective mood in an experimental office workplace. Appl Ergon 2008; 39(6):719-28.

3. Juslén H, Tenner A. Mechanisms involved in enhancing human performance by changing the lighting in the industrial workplace. Int $\mathbf{J}$ Ind Ergon 2005; 35(9):843-55.

4. Van Bommel WJ. Non-visual biological effect of lighting and the practical meaning for lighting for work. Appl Ergon 2006; 37(4):461-6.

5. Stevens RG, Brainard GC, Blask DE, Lockley SW, Motta ME. Adverse health effects of nighttime lighting: comments on American Medical Association policy statement. Am J Prev Med 2013; 45(3):343-6.

6. Li Ch, Sun L, Hu X. A context-aware lighting control system for smart meeting rooms. Systems Engineering Procedia 2012; 4:314-23.

7. de Kort Y, Smolders K. Effects of dynamic lighting on office workers: first results of a field study with monthly alternating settings. Light Res Technol 2010; 42(3):345-360.

8. Scheer FA, Buijs RM. Light affects morning salivary cortisol in human. J Clin Endocrinol Metab 1999; 84(9):3395-8.

9. design_brief_library_lighting [Internet]. 2016 [Last accessed 2016 Sep]. Avaiable from: http://www.lightingassociates.org/i/u/2127806/ f/tech_sheets/design_brief_library_lighting.pdf

10. Rea MS. The IESNA lighting handbook: reference and application. $9^{\text {th }}$ ed. NewYork, United States: Illuminating Engineering Society of North America; 2000.

11. Ghotbi Ravandi MR, Khanjani N, Nadri F, Nadri A, Nadri A, Ahmadian $M$, et al . Evaluation of illumination intensity and ultraviolet radiation at Kerman Medical University libraries. Iran Occupational Health 2012; 8(4):29-35.

12. Kalhor $H$. Illuminating engineering. $2^{\text {nd }}$ ed. Tehran: Publishing Company; 2006. P.113-26. 
13. Javan M, Barakat S, Dehghan H, Yosefi HA, Amiri M, Abram F. Evaluation of lighting intensity in dormitory study halls of Isfahan University of Medical Sciences, Iran. Journal of Health System Research 2013; 9(1):96-103.

14. Nadri H, Nikpey A, Nadri F, Rghalenavi M, Safari Varyani A, Avazpor $\mathrm{M}$, et al . Measurement and design of general illumination in Qazvin Medical Science University student residences. Journal of Ilam University of Medical Science 2013; 20(5):5966.

15. Maghsoodi Moghadam R, Farasati F, Toolabi A, Jafarzadeh Z. Light intensity and ultraviolet radiation in the libraries and computer sites of Ilam Universities. Journal of Health and Development 2014; 2(4):316-25.

16. Zamani M. The moment prediction global solar radiation in Rafsanjan city with neural network. Iranian Journal of Energy 2014; 16(4):15-32

17. Winterbottom M, Wilkins AJ. Lighting and discomform in the classroom. $\mathrm{J}$ Environ
Psychol 2009; 29: 63-75.

18. Kazemzadeh M, Tahbaz M. Measurement and analyzing daylight condition in traditional Kerman houses (Aminian house). Honar-HaYe Ziba (Memari-Va-Shahrsazi) 2013; 18(2):17-26

19. Espinoza LA, Monge-Nájera J. Lighting and noise level in the central facilities of the Costa Rican Distance Education University: health implications for staff and students. Cuadernos de Investigación UNED 2010; 2(1):63-8.

20. Zamanian Z, Barzideh $M$, Ghanbari S, Daneshmandi H. The survey of noise and light effects on body posture during the study in male dormitory of Shiraz University of Medical Sciences. Tolooe-E-Behdasht 2014; 13(4):48-56.

21. Madjidi F, Azimi Pirsaraei SR, Arghami SH. Measurement of the illumination in irregular geometric libraries of Zanjan city with Geospatial Information System (GIS). Journal of Zanjan University of Medical Sciences \& Health Services 2009; 17(66):61-70. 